\title{
Nanoassembled Thin-Film Gas Sensor II. An Intrinsic Highly Sensitive Fibre Optic Sensor for Ammonia Detection
}

\author{
Sergiy Korposh ${ }^{1,2}$, Suguru Kodaira ${ }^{1}$, William Batty ${ }^{2}$, \\ Stephen W. James ${ }^{3}$ and Seung-Woo Lee, ${ }^{1, *}$ \\ ${ }^{1}$ Graduate School of Environmental Engineering, The University of Kitakyushu, \\ 1-1 Hibikino, Kitakyushu 808-0135, Japan \\ ${ }^{2}$ Cranfield University at Kitakyushu, 1-1 Hibikino, Kitakyushu 808-0135, Japan \\ ${ }^{3}$ School of Engineering, Cranfield University, Cranfield, Bedford MK43 0AL, U.K.
}

(Received January 27, 2009; accepted April 23, 2009)

Key words: fibre optic sensor, evanescent wave, layer-by-layer adsorption, porphyrin, ammonia

A layer-by-layer approach was used for the deposition of coatings with a nanometre thickness onto a multimode optical fibre, from which the cladding had been removed, with the aim of realizing a fibre optic ammonia sensor. The film was self-assembled with alternate layers of tetrakis-(4-sulfophenyl) porphine (TSPP) and poly(diallyldimethyla mmonium chloride) (PDDA). The exposure of the assembled film to ammonia induced optical changes in the transmission spectrum of the coated optical fibre, reflecting the characteristic absorption bands (Soret and Q bands) of the assembled TSPP compound. The fibre optic sensor showed a linear sensitivity to ammonia in the concentration range of $0.1-20 \mathrm{ppm}$ and the response and recovery times were less than 3 min with a limit of detection of $0.9 \mathrm{ppm}$ at $706 \mathrm{~nm}$.

\section{Introduction}

The detection of chemical compounds is very important for monitoring outdoor and indoor environments (e.g., air and soil pollutions and sick building syndrome),${ }^{(1)}$ diseases (e.g., allergies and cancer), ${ }^{(2)}$ and dangerous substances (e.g., drugs, hidden bombs, and landmines). ${ }^{(3)}$ Sensitive, reliable and cheap sensors for application in different areas of human activities are still required. A sensor for the detection of ammonia gas is desired but has not yet been effectively achieved in the environmental, automotive, chemical and medical areas. ${ }^{(4)}$ A number of different sensor techniques can be employed for the detection of chemical species through the measurement of electrical, ${ }^{(5)}$ amperometric, ${ }^{(6)}$ optical $^{(7)}$ and other physical ${ }^{(5-9)}$ parameters.

The combination of optical fibre devices with chemically sensitive coatings offers a universal platform for the development of highly sensitive and selective gas sensors. ${ }^{(10)}$ The employment of sensitive elements that can amplify the sensing ability of transducers *Corresponding author: e-mail: leesw@env.kitakyu-u.ac.jp 
has become an essential issue for enhancing the range of applications of the fibre optic sensor. $^{(11-14)}$ Different immobilization procedures based on covalent and noncovalent bonds could be applied to the deposition of sensitive elements onto optical fibres. ${ }^{(15,16)}$ The electrostatic layer-by-layer (LbL) method is a useful tool for the preparation of molecularly assembled films with a good adhesion to the surface. ${ }^{(17,18)}$ The potential of this deposition technique is still expanding because of its versatility and possibility for the fabrication of ordered multilayers including organic, inorganic and biological materials.

Over the past few decades, porphyrins and their derivatives have been considered as sensitive elements for optical sensors ${ }^{(19-22)}$ owing to their specific optical properties in the UV-Vis region. The absorption (or fluorescence) spectra are dependent on their chemical structures induced by metallation, protonation, and aggregation, which make porphyrins useful sensors of their environmental surroundings. ${ }^{(23)}$ The optical spectrum of porphyrins in solid state is altered compared with that in solution, owing to the presence of strong $\pi-\pi$ interactions. ${ }^{(24)}$ The high extinction coefficient $\left(>200,000 \mathrm{~cm}^{-1} \mathrm{M}^{-1}\right)$ makes porphyrin particularly attractive for the development of optical sensors.

In this article, we describe the use of the LbL method for the deposition of a porphyrin thin film onto a multimode silica core/plastic clad optical fibre with the aim of developing an evanescent wave-type fibre-optic gas sensor. A short section of the plastic cladding was replaced with a functional coating of alternate PDDA and TSPP layers. The measurement principle of the device is based on the ammonia-induced optical change in the transmission spectrum of the coated optical fibre. As light travels along the core of the optical fibre, a small portion of energy penetrates the cladding in the form of an evanescent wave, the intensity of which decays exponentially with the distance from the interface between the cladding and the surrounding environment. The penetration depth $\left(d_{\mathrm{p}}\right)$ of the evanescent wave is described by ${ }^{(10)}$

$$
d_{\mathrm{p}}=\frac{\lambda}{2 \pi\left(n_{\mathrm{eff}}^{2}-n_{\mathrm{c}}^{2}\right)^{1 / 2}}
$$

where $\lambda$ is the wavelength of light in free space, $n_{\mathrm{c}}$ is the refractive index of the cladding and $n_{\text {eff }}$ is the effective refractive index of the mode guided by the optical fibre. The deposition of a functional coating layer onto the optical fibre leads to the chemically induced modulation in the transmission spectrum and provides quantitative and qualitative information on the chemical species under examination. The employment of the proposed fibre optic sensor based on the intrinsic evanescent wave has an additional advantage of offering cheap and compact devices, which is due to the combination of light-emitting diode (LED) and photodetector components. Moreover, the sensitivity of the device can be improved by varying the length of the sensing area and thus the process of film deposition will be less time-consuming.

\section{Experimental Methods}

\section{$2.1 \quad$ Materials}

Tetrakis-(4-sulfophenyl) porphine (TSPP) and poly(diallyldimethylammonium chloride) (PDDA, Mw: 200,000-350,000, $20 \mathrm{wt} \%$ in $\mathrm{H}_{2} \mathrm{O}$ ) were purchased from Tokyo 
Kasei, Japan (Scheme 1). Deionized pure water $(18.3 \mathrm{M} \Omega \cdot \mathrm{cm})$ was obtained by reverse osmosis followed by ion exchange and filtration (Nanopure Diamond, Barnstead, Japan). An HCS200 multimode silica core/plastic cladding optical fibre (OF) with core and cladding diameters of 200 and $400 \mu \mathrm{m}$, respectively, was purchased from Ocean Optics (USA). Standard ammonia gas of $100 \mathrm{ppm}$ in dry air was purchased in a cylinder from Japan Air Gases Corp. All of these chemicals were of analytical grade and used without further purification.

\subsection{Optical fibre preparation}

The electrostatic layer-by-layer adsorption method was employed for the deposition of a porphyrin thin film onto a multimode optical fibre (OF). A schematic illustration of this method using PDDA and TSPP is shown in Fig. 1(a). A multimode optical fibre from which the plastic cladding has been removed over an area $1 \mathrm{~cm}$ in length was rinsed in ethanol and distilled water prior to film deposition. The plastic cladding could be easily burned off from the fibre using a burner flame (temperature $<500^{\circ} \mathrm{C}$, the property of the silica core is not changed within this temperature range). One end of the optical fibre was connected to a deuterium-halogen light source (DH-2000-Ball, Mikropack) and the other end was connected to a spectrometer (S1024DW, Ocean Optics). The stripped section of the optical fibre was fixed within a special deposition cell for film preparation, as shown in Fig. 1(b).

Before assembly, the previously stripped section of the optical fibre was cleaned with concentrated sulfuric acid (96\%), rinsed several times with deionized water, and treated with $1 \mathrm{wt} \%$ ethanolic $\mathrm{KOH}$ (ethanol/water $=3: 2, \mathrm{v} / \mathrm{v}$ ) for about $10 \mathrm{~min}$ with sonication to functionalize the surface of the silica core with a $\mathrm{OH}$ group. The fibre core was then rinsed with deionized water, and dried by flushing with dry nitrogen gas. The film is denoted $\left(\mathrm{PDDA}^{+} / \mathrm{TSPP}^{-}\right)_{x}$, where $x=5$ and indicates the number of adsorption cycles. The film was prepared by the alternate deposition of PDDA $\left(5 \mathrm{mg} \mathrm{mL}^{-1}\right.$ in water) and
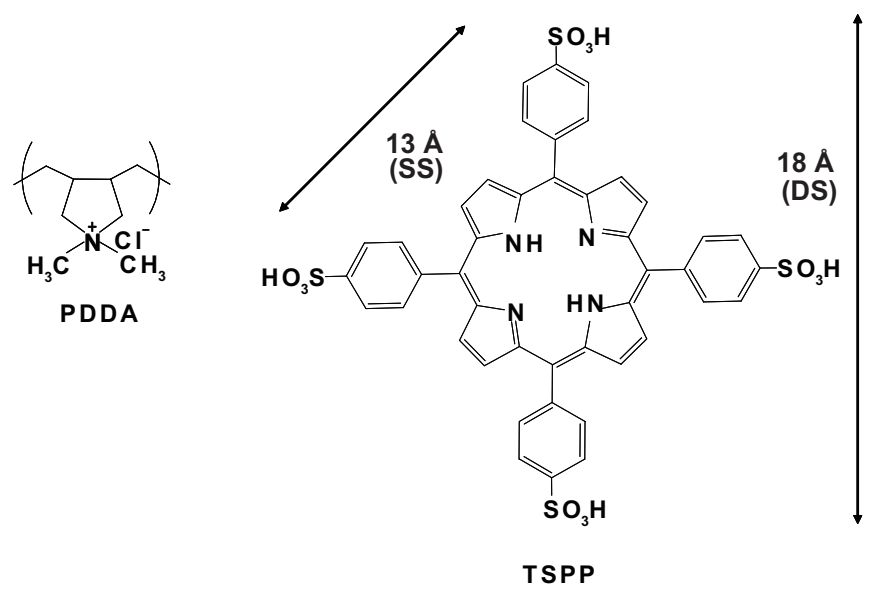

Scheme 1. Structural models of the polycation (PDDA) and porphyrin (TSPP) compounds used in this study:(17) SS, side length of square; DS, diagonal length of square. 
(a)

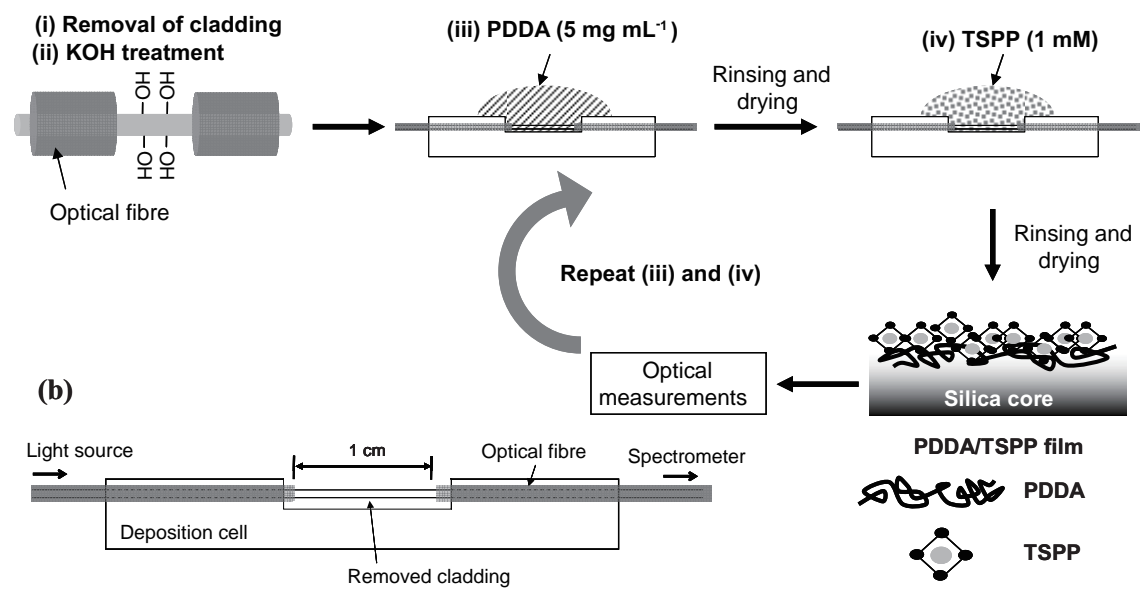

Fig. 1. (a) Schematic illustration of the layer-by-layer adsorption of TSPP and PDDA on a multimode optical fibre and (b) deposition cell used for coating the optical fibre.

TSPP ( $1 \mathrm{mM}$ in water) (where one cycle is considered to be a combined $\mathrm{PDDA}^{+} / \mathrm{TSPP}^{-}$ bilayer) by introducing a coating solution $(150 \mu \mathrm{L})$ into the deposition cell with intermediate processes of water washing and drying by flushing with nitrogen gas being undertaken between the application of layers. In every case, the outermost surface of the alternate film was TSPP. The assembly process was monitored using an S1024DW spectrometer (Ocean Optics). The absorbance was determined by taking the logarithm of the ratio of the transmission spectrum of the coated fibre, $T(\lambda)$, to the transmission spectrum measured prior to film deposition, $T_{0}(\lambda)$,

$$
A(\lambda)=-\log \frac{T(\lambda)}{T_{0}(\lambda)}
$$

The assembly process was characterised and the thickness of the film was measured using a quartz crystal microbalance technique, as described in our previous work. ${ }^{(25)}$

\subsection{Optical measurements}

The desired gas concentrations were produced using a two-arm flow system, as shown in Fig. 2(a). Dry compressed air and ammonia gas of $100 \mathrm{ppm}$ were passed through two flowmeters, and the two flows were recombined with a final analyte concentration (volume fraction) $c$ in the measurement chamber calculated using,

$$
c=\frac{L_{1} \cdot z}{L_{1}(1+z)+L_{2}},
$$


(a)

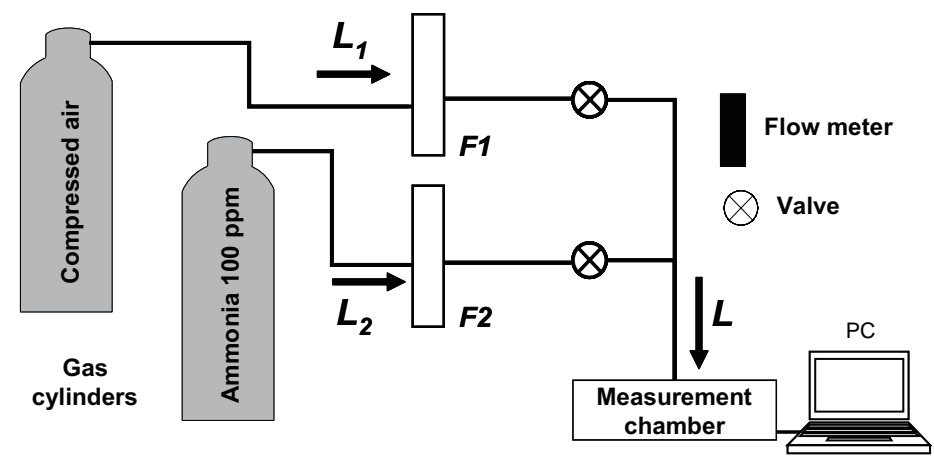

(b)

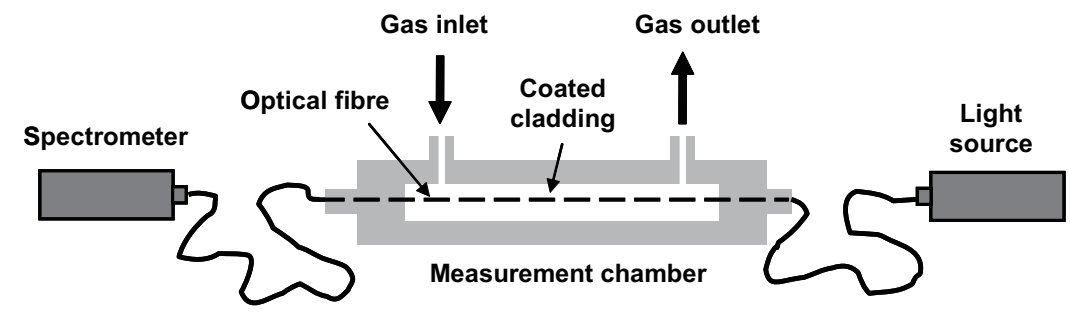

Fig. 2. (a) Apparatus of a two-arm flow gas generation system: F1 and F2 are flowmeters; $L_{i}$ represents the concentration of the gases in the different arms of the system. (b) Schematic illustration of the measurement setup: light source, Ocean optics light source emitting light in the range of wavelengths from 200 to 1,100 nm; spectrometer, Ocean Optics S1024DW spectrometer.

where $z$ is the mole fraction of ammonia, and $L_{1}$ and $L_{2}$ are the flow rates of dry air and ammonia gas, respectively. $L$ (where $L=L_{1}+L_{2}$ ) was maintained at $1 \mathrm{~L} \mathrm{~min}^{-1}$ and ammonia concentration was adjusted by varying $L_{1}$ and $L_{2}$. A custom designed sensor chamber made of Teflon (Fig. 2(b)) was used to estimate the ammonia response. The optical fibre coated with the functional film was inserted in the chamber and connected to the light source and spectrometer, as shown in Fig. 2(b).

The sensor response at a given analyte concentration was measured every second by recording the transmission spectrum of the film deposited on the optical fibre. The difference spectrum was plotted by subtracting a spectrum measured at a given analyte concentration from the spectrum recorded in the presence of dry air. The baseline spectrum of each experiment was recorded by passing dry air through the measurement chamber until the signal measured at wavelengths of 350, 470 and $706 \mathrm{~nm}$ reached equilibrium. The dynamic sensor response was also measured at the same wavelengths.

The optical fibre sensor response $(S R)$ was calculated using

$$
S R=100\left(I_{0}-I\right) / I_{0}
$$

where $I_{0}$ and $I$ describe the light intensities of the $\mathrm{PDDA}^{+} / \mathrm{TSPP}^{-}$film in the absence and presence of the analyte gas, respectively, measured at a given wavelength. 


\section{Results and Discussion}

\subsection{Optical spectra of PDDA $A^{+} / T_{S P P}^{-}$alternate layers}

The assembly of the PDDA and TSPP layers after each deposition cycle was measured by monitoring the optical change in the transmission spectra of the optical fibre. Figure 3(a) shows the evolution of the transmission spectrum of the optical fibre during the deposition of a five-cycle $\mathrm{PDDA}^{+} / \mathrm{TSPP}^{-}$thin film. The absorbance spectra were derived from the transmission spectra using eq. (2). The largest absorbance due to the deposition of the ( $\left.\mathrm{PDDA}^{+} / \mathrm{TSPP}^{-}\right)$bilayer was observed at a wavelength of $420 \mathrm{~nm}$, which corresponds to the Soret band. The absorbance increased in proportion to the number of adsorption cycles (Fig. 3(b)). The absorbance spectra of the (PDDA ${ }^{+} / \mathrm{TSPP}^{-}$) film are characterized by a double peak in the Soret band occurring at 420 and 480 $\mathrm{nm}$, and by a pronounced peak of the Q band at $706 \mathrm{~nm}$. These spectral characteristics suggest that TSPP molecules exist in the J-aggregate state, in which the absorbance maxima of the Soret and Q bands are redshifted compared with those in the monomeric state. ${ }^{(17,26,27)}$ The aggregation state of TSPP and hence its spectral features are controlled by the protonation/deprotonation of the porphyrin pyrrole ring. ${ }^{17)}$ Figure 3(c) shows the absorbance change monitored at two Soret bands (420 and $480 \mathrm{~nm}$ ) and at the Q band $(706 \mathrm{~nm})$ versus the number of adsorption cycles.

\subsection{Optical response to ammonia}

Ammonia-induced optical changes in the transmission spectrum of the $\left(\mathrm{PDDA}^{+} / \mathrm{TSPP}^{-}\right)_{5}$ film are shown in Fig. 4. As ammonia concentration increases from 0 to $20 \mathrm{ppm}$, the intensity change occurs at several wavelengths; at $706 \mathrm{~nm}$, intensity increases, whereas at 350 and $470 \mathrm{~nm}$ it decreases. Upon exposure of the $\left(\mathrm{PDDA}^{+} / \mathrm{TSPP}^{-}\right)_{5}$ film to ammonia, the largest intensity change was observed at $706 \mathrm{~nm}$. The interaction between ammonia and TSPP molecules leads to the deprotonation from the pyrolle ring and hence affects the interaction between TSPP molecules. Similarly, the largest change in absorbance is observed at $706 \mathrm{~nm}$ (Q band), which is attributed to the aggregation structure of TSPP. ${ }^{(26)}$

The dynamic sensor response of the $\left(\mathrm{PDDA}^{+} / \mathrm{TSPP}^{-}\right)_{5}$ film to ammonia was monitored at 350, 470 and $706 \mathrm{~nm}$ (Fig. 5(a)). As can be seen from the result, the sensor response is fully reversible for low ammonia concentrations (up to $1 \mathrm{ppm}$ ). However, at higher concentrations the recovery time of the sensor response takes longer to return to the base line. The base line may be recovered when flushed with air for a sufficient time, as shown in Fig. 5(a). Alternatively, the sensor response can be regenerated by rinsing for a few seconds in distilled water. ${ }^{(25)}$ The calibration curve at each wavelength was plotted from the recorded spectra at given ammonia concentrations. The sensor shows linear responses at all wavelengths for a wide concentration range from 0.1 to $20 \mathrm{ppm}$ and the highest sensitivity was observed at $706 \mathrm{~nm}$ (Fig. 5(b)).

Table 2 shows a summary of the sensor parameters, including sensitivity, response and recovery times and limit of detection $(L O D)$ measured at different wavelengths. The response and recovery times $\left(t_{90}\right)$ of the sensor to increasing ammonia concentration were within 1.6-2.5 and 1.8-3.2 min, respectively (see Fig. 5(a)). The sensitivity of the sensor depends on the wavelength and has different directions; for 350 and $470 \mathrm{~nm}$ it is 


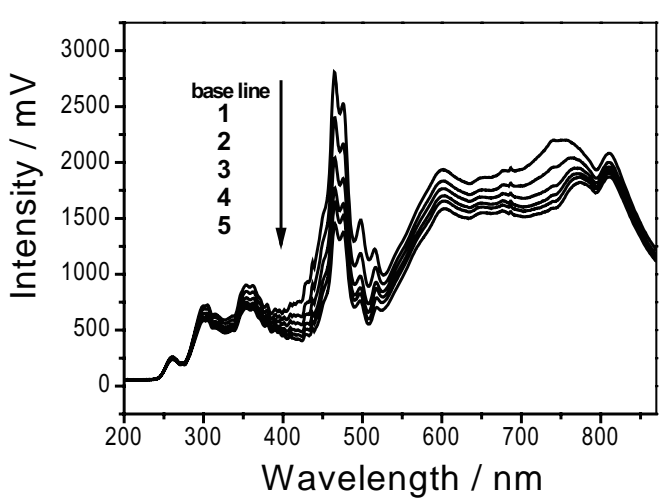

(a)

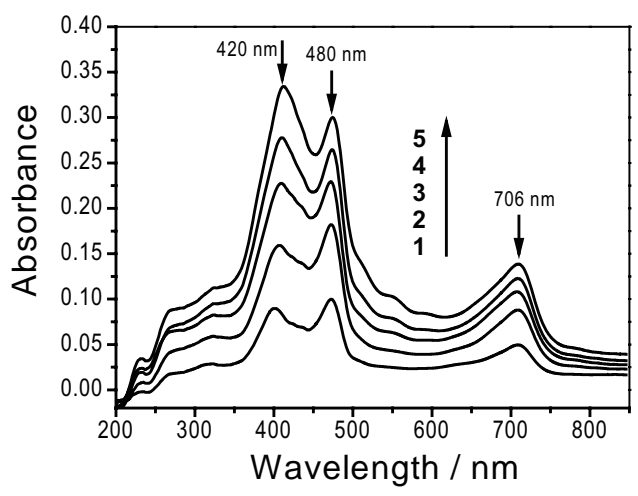

(b)

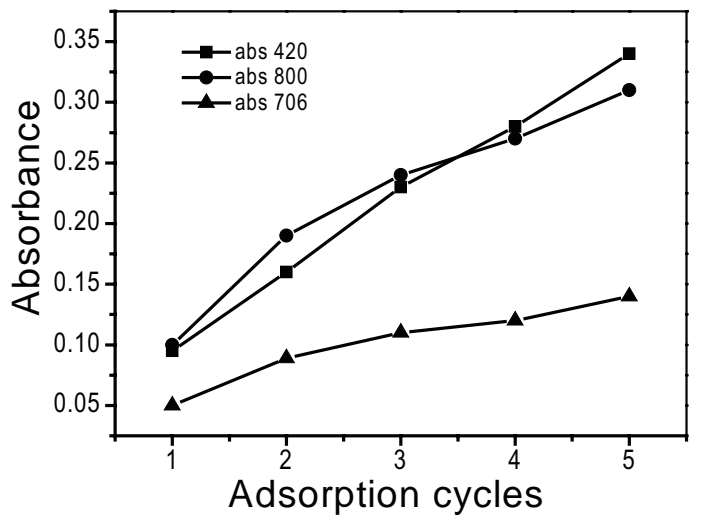

(c)

Fig. 3. Evolution of the spectrum of a multilayer film of PDDA $^{+} / \mathrm{TSPP}^{-}$that was deposited onto a 200- $\mu \mathrm{m}$-core-diameter multimode optical fibre with a stripped silica core of $1 \mathrm{~cm}$ : (a) transmission spectra (data as measured); (b) absorbance spectra (derived from the transmission spectra using eq. (2)); (c) absorbance change due to film deposition monitored at wavelengths of $420 \mathrm{~nm}$ (squares), $480 \mathrm{~nm}$ (circles), and $706 \mathrm{~nm}$ (triangles).

negative and for $706 \mathrm{~nm}$ it is positive. The highest sensitivity was measured at $706 \mathrm{~nm}$, corresponding to the optical change of the Q band of TSPP. The current sensor system has a limit of detection $(L O D)$ on the ppm order ranging from 0.9 to $2.6 \mathrm{ppm}$. The limit of detection was defined according to $L O D=3 \sigma / \mathrm{m}$, where $\sigma \approx 0.31$ is the standard deviation, and $m$ is the slope $(\Delta I / \Delta c)$ of the calibration curve, where $c$ is the ammonia concentration and $I$ is the measured intensity $(\mathrm{mV}) .{ }^{(28)}$ The presence of different features 


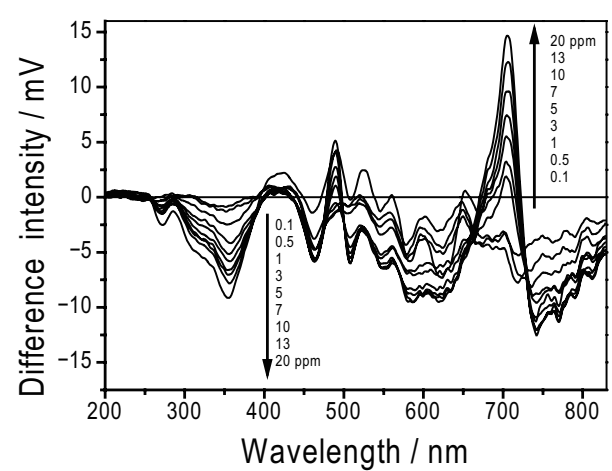

Fig. 4. Optical transmission difference spectra of the optical fibre consisting of a five-cycle $\mathrm{PDDA}^{+} / \mathrm{TSPP}^{-}$alternate film for ammonia concentrations ranging from $0-20 \mathrm{ppm}$. Difference spectra derived from Fig. 3(a) were obtained by subtracting a spectrum measured in ammonia atmosphere from a spectrum measured in air.

(a)
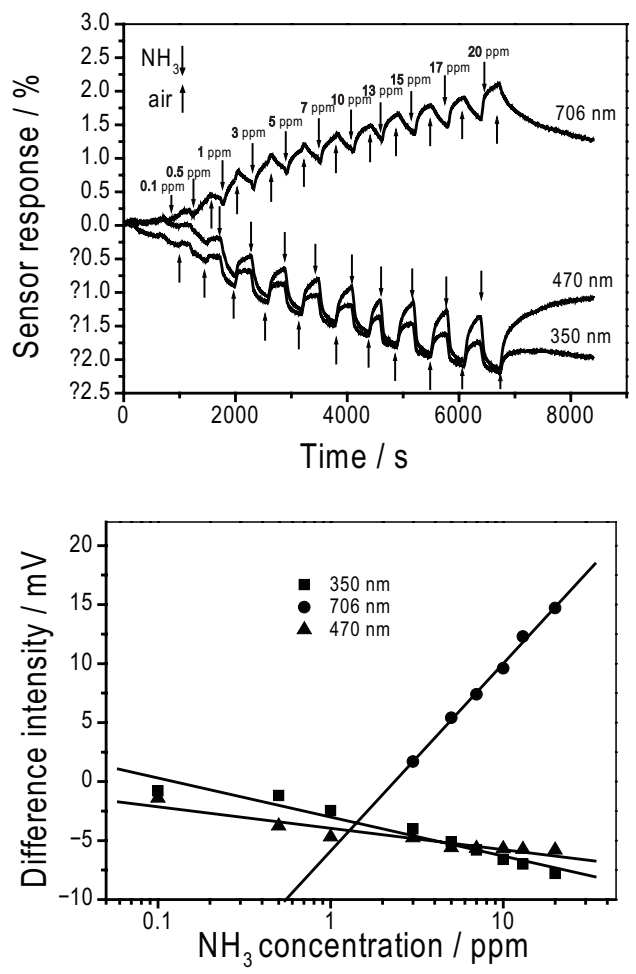

Fig. 5. (a) Dynamic response of the optical fiber consisting of a five-cycle $\mathrm{PDDA}^{+} / \mathrm{TSPP}^{-}$ alternate film for ammonia concentrations ranging from 0-20 ppm at 350, 470, and $706 \mathrm{~nm}$. (b) Calibration curves at $350 \mathrm{~nm}$ (squares), $470 \mathrm{~nm}$ (rhombuses), and $706 \mathrm{~nm}$ (circles). Lines show the linear fitting and are provided only as guides for the eye. 
Table 2

Summary of the sensor parameters (sensitivity, response and recovery times, and limit of detection) for the five-cycle $\mathrm{PDDA}^{+} / \mathrm{TSPP}^{-}$film.

\begin{tabular}{cccccc}
\hline $\begin{array}{c}\text { Wavelength } \\
\text { / nm }\end{array}$ & $\begin{array}{c}{ }^{\text {aSensitivity }} \\
\text { / slope }\end{array}$ & $\begin{array}{c}{ }^{b} \text { Response time } \\
\text { /min }\end{array}$ & $\begin{array}{c}{ }^{b} \text { Recovery time } \\
\text { / min }\end{array}$ & $\begin{array}{c}\text { Linear range } \\
\text { / ppm }\end{array}$ & $\begin{array}{c}{ }^{c} L O D \\
/ \mathrm{ppm}\end{array}$ \\
\hline 350 & $-0.50 \pm 0.08$ & 2.0 & 1.8 & $0.1-20$ & 1.90 \\
470 & $-0.35 \pm 0.06$ & 2.5 & 2.4 & $0.1-20$ & 2.65 \\
706 & $0.98 \pm 0.07$ & 1.6 & 3.2 & $0.1-20$ & 0.90 \\
\hline
\end{tabular}

aSlope calculated from the calibration curve (Fig. 5(b)).

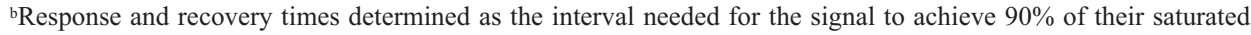
condition when measured of an $\mathrm{NH}_{3}$ concentration of $10 \mathrm{ppm}$.

${ }^{\circ} L O D$ : limit of detection.

in the optical spectrum after exposing the $\mathrm{PDDA}^{+} / \mathrm{TSPP}^{-}$film to ammonia offers the ability to create a low-cost fibre optic sensor by selecting an LED and a photodiode with parameters that will coincide with the wavelength at which the largest ammonia-induced changes were observed $(706 \mathrm{~nm})$.

\subsection{Sensing mechanism}

Porphyrin compounds can be used as sensitive elements for optical sensors because their optical properties (absorbance and fluorescence features) depend on the environmental conditions in which the chemicals are present. ${ }^{(29)}$ Generally, the change in porphyrin absorption spectra is induced by (i) solvent effects, (ii) redox reactions, (iii) the protonation or metallation of core nitrogen atoms, (iv) $\pi-\pi$ electron interaction, (v) electronic changes due to structural changes such as flattening or distortion, or (vi) interactions between porphyrins (aggregation). ${ }^{(29)}$ The alternation of the spectral features observed when the $\left(\mathrm{PDDA}^{+} / \mathrm{TSPP}^{-}\right)_{5}$ film was exposed to ammonia (Fig. 4) suggests the following mechanisms of the interaction between TSPP and ammonia gas:

(i) Interaction between ammonia and porphyrin compounds leads to the deprotonation of the TSPP pyrolle ring and the formation of ammonium ions, as shown in Scheme 2. This deprotonation leads to the disruption of J-aggregation and is mainly accompanied by spectral changes occurring at 470 and $706 \mathrm{~nm} ;(17,26,29)$

(ii) We can speculate that a decrease in the transmittance noted at $350 \mathrm{~nm}$ may be attributed to the distortion of the aggregation structure due to the adsorption of ammonia. ${ }^{(29)}$

The above-mentioned sensing mechanisms are mainly based on the dissociation of J-aggregated TSPP molecules and the original structure of the $\mathrm{PDDA}^{+} / \mathrm{TSPP}^{-}$film can be recovered by protonation from ammonium ions. The future challenge is to test the selectivity of the proposed device. Preliminary results obtained by exposing the fibre optic sensor coated with the five-cycle $\mathrm{PDDA}^{+} / \mathrm{TSPP}^{-}$film to some volatile organic compounds (VOCs) revealed a higher selectivity towards amine compounds (data not shown). 

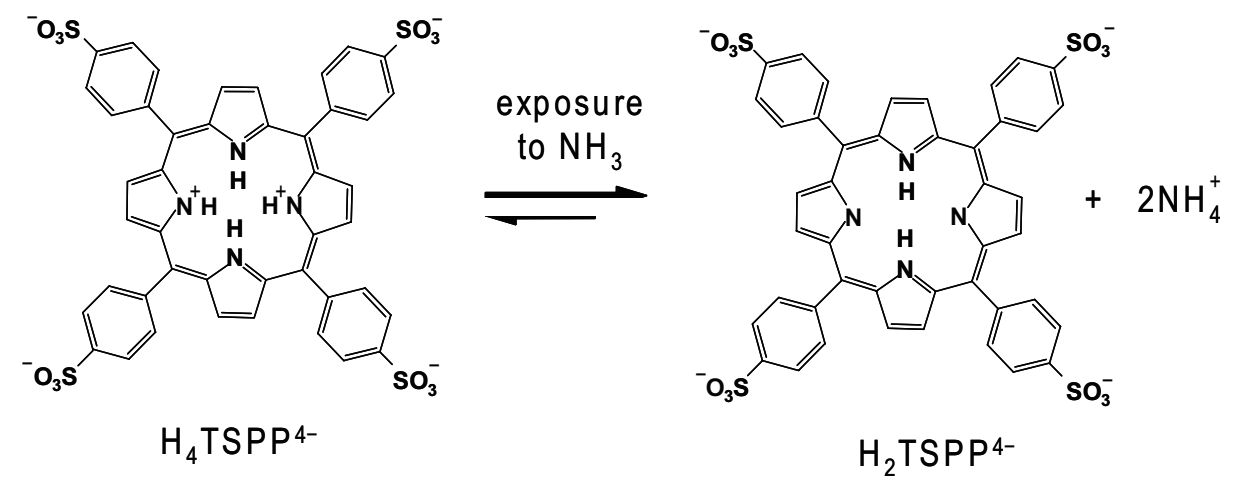

Scheme 2. Schematic representation of the interaction between ammonia and TSPP compounds in the $\mathrm{PDDA}^{+} / \mathrm{TSPP}^{-}$film.

\section{Conclusion}

A fibre optic ammonia sensor based on a $\mathrm{PDDA}^{+} / \mathrm{TSPP}^{-}$alternate thin film deposited on the core of a multimode optical fibre using a layer-by-layer approach is demonstrated. The intensity of the light propagating through the optical fibre decreases proportionally with the increase in the thickness of the TSPP layers deposited over the optical fibre. The exposure of the five-cycle $\mathrm{PDDA}^{+} / \mathrm{TSPP}^{-}$film to ammonia induces changes in the absorption spectrum via the deprotonation of TSPP, which could be observed in the transmission spectrum of the coated optical fibre. The highest sensitivity $\left(0.98 \mathrm{mV} \mathrm{ppm}^{-1}\right)$ was observed when measured at $706 \mathrm{~nm}$, which corresponds to the $\mathrm{Q}$ band of the porphyrin compound; for low-cost-sensor development it is possible to use a simple LED-photodiode system operating at approximately $700 \mathrm{~nm}$. The sensor showed a linear sensitivity to the presence of ammonia with a limit of detection of $0.9 \mathrm{ppm}$ in the concentration range of $0.1-20 \mathrm{ppm}$ and the sensor response and recovery times were less than $4 \mathrm{~min}$. The demonstrated sensor offers an opportunity for the detection of different chemicals by coating an optical fibre with an appropriate sensitive material. Further work is needed to optimize sensor performance and to study the effects of coating thickness, relative humidity and presence of the other chemical compounds on sensor parameters.

\section{Acknowledgment}

This work was supported by MEXT via the Kitakyushu knowledge-based Cluster Project. 


\section{References}

1 B. Seifert, N. Englert, H. Sagunski and J. Witten: Proc. 8th Int. Con. on Indoor Air Quality and Climate 1999 (Indoor Air, Edinburgh, Scotland, 1999) p. 499.

2 C. D. Natale, A. Macagnano, E. Martinelli, R. Paolesse, G. D'Arcangelo, C. Roscioni, A. Finazzi-Agrò and A. D'Amico: Biosens. Bioelectron. 18 (2003) 1209.

3 N. Takahara, D.-H. Yang, M.-J. Ju, K. Hayashi, K. Toko, S.-W. Lee and T. Kunitake: Chem. Lett. 35 (2006) 1340.

4 B. Timmer, W. Olthuis and A. Van den Berg: Sens. Actuators, B 107 (2005) 666.

5 F. Winquist, R. Bjorklund, C. Krantz-Rülcker, I. Lundström, K. Östergren and T. Skoglund: Sens. Actuators, B 111,112 (2005) 299.

6 R. Knake, P. Jacquinot, A. W. E. Hodgson and P. C. Hauser: Anal. Chim. Acta 549 (2005) 1.

7 B. G. Kermani, I. Fomenko, T. Kotseroglou, B. Forood, L. Clark, D. Barker and M. Lebl: Sens. Actuators, B 117 (2006) 282.

8 H.-B. Lin snd J.-S. Shih: Sens. Actuators, B 92 (2003) 243.

9 C. K. Ho, A. Robinson, D. R. Miller and M. J. Davis: Sensors 5 (2005) 4.

10 K. T. V. Grattan and B. T. Meggitt: Chemical and Environmental Sensing (Kluwer Academic Publisher, Boston, 1999).

11 C. Munkholm, D. R. Walt and F. P. Milanovich: Talanta 35 (1988) 100.

12 C. Bariani, I. R. Matias, I. Romeo, J. Garrido and M. Laguna: Sens. Actuators, B 76 (2001) 25.

13 T. Grady, T. Butler, B. D. MacCraith, D. Diamond and A. M. McKervey: Analyst 122 (1997) 803.

14 C. Malins, A. Doyle, B. D. MacCraith, E. Kvasnik, M. Landl, P. Šimon, L. Kalvoda, R. Lukaš, K. Pufler and I. Babusík: J. Environ. Monit. 1 (1999) 417.

15 O. S. Wolfbeis, N. V. Rodriguez and T. Werner: Microchim. Acta 108 (1992) 133.

16 T. L. Blair, T. Cynkowski and L.G. Bachas: Anal. Chem. 65 (1993) 945.

17 K. Ariga, Y. Lvov and T. Kunitake: J. Am. Chem. Soc. 119 (1997) 2224.

18 S.-W. Lee, I. Ichinose and T. Kunitake: Langmuir 14 (1998) 2857.

19 A. A. Umar, M. M. Salleh and M. Yahaya: Eur. Phys. J. Appl. Phys. 29 (2005) 215.

20 A. Morales-Bahnik, R. Czolk and H. J. Ache: Sens. Actuators, B 18,19 (1994) 493.

21 J. Spadavecchia, G. Ciccarella, P. Siciliano, S. Capone and R. Rella: Sens. Actuators, B 100 (2004) 88.

22 D. B. Papkovsky: Sens. Actuators, B 11 (1993) 293.

23 M. Monajjemi, H. Aghaie and F. Naderi: Biochemistry (Moscow) 72 (2007) 652.

24 G. A. Schick, I. C. Schreiman, R. W. Wagner, J. S. Lindsey and D. F. Bocian: J. Am. Chem. Soc. 111 (1989) 1344.

25 S. O. Korposh, N. Takahara, J. J. Ramsden, S.-W. Lee and T. Kunitake: J. Biological Physics and Chemistry 6 (2006) 125.

26 P. Gregory van Patten, A. P. Shreve and R. J. Donohoe: J. Phys. Chem. B 104 (2000) 5986.

27 V. Snitka, M. Rackaitis and R. Rodaite: Sens. Actuators, B 109 (2005) 159.

28 M. E. Swartz and I. S. Krull: Analytical Method Development and Validation (Marcel Dekker, Inc., New York, 1997).

29 S. Takagi, M. Eguchi, D. A. Tryk and H. Inoue: J. Photochem. Photobiol., C 7 (2006) 104. 